\title{
EL CANALLITA MACHIRULO: UNA APROXIMACIÓN A LAS MASCULINIDADES DEL ROCK ESPAÑOL
}

\author{
David Vila Diéguez \\ California State University at Monterey Bay (CSUMB)
}

\section{Resumen}

En un tiempo en el que es común despotricar contra el reggaetón y el trap por su supuesto carácter machista, es de imperiosa necesidad reflexionar sobre los tipos de masculinidades que otros estilos como el rock han venido construyendo desde muchos años antes. Este artículo representa un primer acercamiento a dicho empeño. Partiendo de conceptos como la hipermasculinidad, la masculinidad hegemónica, la camaradería masculina y otros, este ensayo realiza una lectura de la producción cultural de bandas como Coz, Lujuria o Los Zigarros, para detallar el tipo de masculinidades que en ellas se proyectan. Para ello, el artículo se basa en un arquetipo que denomina como 'el canallita machirulo'.

Palabras clave: MASCULINIDADES, ROCK \& ROLL, HIPERMASCULINIDAD, GÉNERO, ESPAÑA

\section{THE COCKY MISOGYNIST: AN APPROXIMATION TO THE MASCULINITIES OF SPANISH ROCK}

\section{Abstract}

In times when criticizing reggaeton and trap for their alleged sexist character has become way too common, it is crucial to reflect on the kind of masculinities constructed by other music styles that were there many years before them. This article sets out to do so with the case of Spanish rock. Drawing from concepts such as hypermasculinity, hegemonic masculinity, and male bonding, among others, this essay conducts a close reading of the cultural productions of bands such as Coz, Lujuria, or Los Zigarros, as a way to study the masculinities put forward in their discourse. In order to do so, the article relies on an archetype it calls 'the cocky misogynist'.

Keywords: MASCULINITIES, ROCK \& ROLL, HYPERMASCULINITY, GENDER, SPAIN

\footnotetext{
Vila Diéguez, David. 2021. “El canallita machirulo: Una aproximación a las masculinidades del rock español". AusArt 9 (1): 261-271. D0I: 10.1387 /ausart.22634
}

\section{AUSART}


¡Qué asco! ¡Qué asco nos dan!

Ensucian de mierda tu sexualidad

No importa la forma, todo les da igual

¡Qué asco! ¡Qué asco nos dan!

Lo más gracioso es iqué casualidad!

somos las víctimas de la moral.

Belladona, "Macho de primera"

No hace mucho me encontraba involucrado en una conversación que se viene repitiendo muy a menudo entre muchos de mis colegas músicos: la discusión sobre el supuesto machismo de la música contemporánea y más concretamente del reggaetón y del trap. Al parecer, la juventud de hoy en día ha perdido el respeto hacia la mujer y eso se ve claramente en el tipo de letras que los artistas de trap y reggaetón escriben. Pareciera que hasta la llegada de este tipo de músicas no hubieran existido ni el machismo ni los feminicidios. La otra parte importante de esta conversación suele ser la defensa nostálgica del rock como el verdadero abanderado de una juventud rebelde y comprometida. Sin embargo, una rápida escucha a canciones como "Hoy voy a asesinarte" de Siniestro Total, "La maté porque era mía" de Platero y tú o "La mataré" de Loquillo y los trogloditas parecería indicar justamente todo lo contrario. Inspirado por este tipo de conversaciones, el siguiente artículo representa una aproximación al estudio de las masculinidades del rock español con el objetivo de explicitar y contribuir a neutralizar algunas de las instancias de machismo en él presentes.

En esta ocasión se obviará por completo el rock internacional porque lo que interesa es ahondar en las características concretas del rock español y su posible influencia en este territorio. Para todo ello me basaré en un arquetipo que iré construyendo a medida que avance el ensayo y que he tenido a bien Ilamar 'el canallita machirulo'. El análisis seguirá un método interpretativo semiótico basado en los primeros estudios culturales desarrollados por la escuela de Birmingham con nombres como los de Dick Hebdige o Stuart Hall a la cabeza. En este sentido, el análisis partirá del presupuesto posestructuralista de que el significado de un texto es múltiple y que se construye en el momento preciso de su consumo -y no de su construcción- y se constituirá mediante la observación y especulación de una posible interpretación entre muchas otras. Dicho de otro modo, este ensayo no atenderá a informantes o a las declaraciones de consumidores de rock español para desentrañar la interpretación mayoritaria que estos han hecho del mismo, sino que establecerá 
conexiones entre diferentes aspectos del rock español a través del prisma de la masculinidad para proponer una posible interpretación que no siempre tiene por qué funcionar de manera consciente entre sus consumidores.

Desde sus comienzos en Estados Unidos a finales de los años 40 y principios de los 50, el rock and roll siempre se ha caracterizado por su rebeldía y su oposición a la moralidad puritana de la sociedad occidental. Desde los pánicos morales (Cohen 1972) ${ }^{1}$ causados por las sensuales caderas de Elvis Presley (Shumway 2014, 24), a los movimientos contraculturales de los años 60 (Eyerman \& Jamison 1998), el rock ha sido una importante herramienta a través de la cual los jóvenes se han rebelado contra las normas de comportamiento que la sociedad de la época les quería imponer. A pesar de ello, tal y como Simon Frith y Angela McRobbie advierten, dentro de esta dimensión liberadora el rock nunca ha representado la libre expresión de una sexualidad socialmente reprimida, sino que lo que ha hecho ha sido construir una manera concreta de entender la sexualidad a través de su discurso musical y poético (Frith \& McRobbie 1990, 318) ${ }^{2}$. Partiendo de esta premisa, coincido con Susan McClary cuando dice que "music does not just passively reflect society; it also serves as a public forum within which various models of gender organization (along with many other aspects of social life) are asserted, adopted, contested and negotiated" (McClary 1991, 8) y la pregunta que intentaré responder en este ensayo no es tanto cómo el rock español representa masculinidades auténticas existentes en la vida real, sino cuáles son algunas de las masculinidades que este construye en su discurso. Esta perspectiva es determinante porque lo verdaderamente importante no es "how true a piece of music is to something else, but how it sets up the idea of 'truth' in the first place" (Frith 2007, 121), sobre todo teniendo en cuenta que "music works materially to give people different identities, to place them in different social groups" (ibíd., 124) y que eso incluye la manera en que se construyen las identidades masculinas que después son reproducidas en el mundo real.

\section{EL CANALLITA MACHIRULO}

En 1980, el grupo madrileño Coz, formado enteramente por hombres, publica su primer disco, Más sexy, en el cual incluyen una canción homónima que representa su primer sencillo. En esta canción la voz cantante pide constan- 
temente a una segunda persona singular mujer, "tú", que sea más sexy en diferentes contextos:

Sexy en la piscina, en la comisaría

Sexy en la oficina, ponte sexy todo el día

Sexy por la noche cuando el vecino te mira

Sexy autonomía, sexy l'estatut

Sexy Mata-Hari, teleñeco, barbazul

En definitiva, siempre sexy para satisfacer el placer de una voz masculina que impone su dominio sobre una mujer abstracta que viene a representar a todas las mujeres en general. La letra de esta canción llega incluso a oponerse a un feminismo malentendido cuando pide que sea sexy "aunque las progres digan que has de ser más fría" y quita peso al acoso al pedir que sea sexy "aunque en la calle te digan alguna grosería". De esta forma, en esta canción no sólo se presenta una mirada masculina y una cosificación de la mujer tal y como Laura Mulvey las entiende al decir que "woman displayed as sexual object is the leitmotif of erotic spectacle" (Mulvey [1974] 1999, 62), sino que además la voz masculina ejerce una subyugación bastante literal al dirigirse directamente a la mujer y ordenarle cómo es que debe comportarse o cómo es que debe vestirse ("Muñequita ponte tacón ... Pruébate una talla menor ... Desabróchate otro botón ... Ponte falda de Marilyn"). Esto es especialmente llamativo en la parte en que el cantante indica a esta mujer abstracta que "pued[e] ser sexy como el rock and roll", tras lo cual un coro de mujeres infantilizadas con voces dulces y agudas responde obedientemente repitiendo al unísono que "pued[en] ser sexy[s] como el rock and roll".

Esta representación del género es también perceptible en el vídeo musical que acompaña a la canción. En él encontramos a un grupo de cuatro hombres sobre un escenario de dos niveles, uno al frente algo más abajo -donde se encuentran ellos- y otro atrás ligeramente más alto donde se ve a dos mujeres bailando. El video abre con la imagen del bajista y los dos guitarristas moviendo los mástiles de sus instrumentos arriba y abajo y de atrás hacia delante al ritmo de la música casi emulando una premonitoria penetración simbólica que marca el tono de lo que se va a ver en el resto del vídeo. Mientras tanto las mujeres bailan de espaldas moviendo sus nalgas en dirección a la cámara. Son especialmente destacables los movimientos del guitarrista solista al tocar los solos apoyando la guitarra en la zona umbilical y apuntando 
hacia delante con el mástil mientras el vídeo alterna esto con imágenes de las mujeres dando golpes de cadera hacia delante a modo de coreografía. También es notable el hecho de que las mujeres aparezcan bailando calladas durante todo el trascurso del vídeo excepto cuando llega la parte en la que responden al cantante obedientemente diciendo que "pued[en] ser sexy[s] como el rock and roll".

Todo esto crea una orgía simbólica llena de momentos sexuales en la que el hombre es claramente el que lleva el mando manteniendo a la mujer en silencio y como objeto de deseo que sólo habla para confirmar que ha entendido las órdenes que le ha dado su 'amo'. Esto queda también marcado espacialmente por la separación de escenarios donde las mujeres ocupan un lugar secundario al fondo de la imagen sin compartir el escenario principal con los miembros de la banda. Además, esta separación contribuye a una cierta hermandad o camaradería masculina entre todos los miembros del grupo, quienes disfrutan juntos de la subyugación de estas dos mujeres que bailan -y de las otras a las que la canción se dirige- mientras sonríen y miran hacia atrás para verlas cuando dicen que "pued[en] ser sexy[s] como el rock and roll", lo cual podría tener mayores implicaciones simbólicas si pensamos en las tan recurrentes violaciones en grupo de hoy en día. Con esto, obviamente, no estoy comparando la actuación del grupo con una violación grupal, ni estoy sugiriendo que quien escuche esta canción va pensar en cometer una. Lo que digo es que esa cosificación de la mujer acompañada de la risa y camaradería masculina es a menudo el tipo de masculinidad que reproducen los participantes en una violación grupal. Una camaradería que empuja a que uno no quiera ser visto como menos 'hombre' que los demás (Kimmel 1994; Pascoe 2007) y que, por lo tanto, contribuye a que uno no se detenga, y que, además, comparte y divide la responsabilidad del acto que se está cometiendo contribuyendo a disminuir el sentimiento de culpa. El mismo tipo de camaradería machista que podríamos encontrar en un grupo de amigos que cuentan y se ríen de chistes en los que se degrada a la mujer o en un grupo de amigos que presume de sus numerosas conquistas sexuales cosificando a la mujer (Keith 2021, vi). Lo que en inglés se ha denominado como 'male bonding' y que según autores como Kimmel o Michael Flood es un ritual a través del cuál los hombres juzgan, conceden, y compiten para reafirmar su masculinidad los unos frente a los otros (Flood 2008, 341). Además, puestos en el contexto de un concierto, esta camaradería se extendería también al público masculino allí presente multiplicando exponencialmente su influencia.

Este tipo de masculinidad pseudorebelde e hipersexualizada encarna el arquetipo de lo que en este ensayo llamo el 'canallita machirulo', un personaje 
que, mientras que parece romper con los tabúes heredados del franquismo y de la moralidad puritana de la dictadura presentándose como trasgresor, es al mismo tiempo una clara figura opresora hacia la mujer. Es precisamente la ruptura con estos tabúes lo que constituye esa sensación de rebeldía y progresismo que oscurece el machismo que a su vez encierra. En cierto sentido, este canallita machirulo se erige como el representante de lo que Frith y McRobbie han denominado 'cock rock' y al que, a partir de ahora, me referiré por su traducción literal como 'rock polla'. Según estos autores, el rockero polla usa sus instrumentos no exclusivamente para tocar sino también para dar rienda suelta a su imaginación 'macho' y tanto las guitarras como los micros representan símbolos fálicos (Frith \& McRobbie 1990, 319). De esta manera, además, contribuyen a consolidar el rock como una tecnología del género en términos foucaltianos, es decir, como una fuerza a través de la cual "masculinity is reinforced and multiplied in its many discursive spaces" (Coates 1997, 52).

De esta manera, el rock se establece como uno de los géneros musicales contemporáneos que mejor representan la idea de la hipermasculinidad en España. Michael S. Kimmel y Amy Aronson definen la hipermasculinidad como "sets of behaviors and beliefs characterized by unusually highly developed masculine forms as defined by existing cultural values" (Kimmel \& Aronson $2004,418)$. En otras palabras, la expresión exagerada de los rasgos estereotípicos que caracterizan la masculinidad tradicional tales como la fortaleza, el control, el poder, una alta capacidad sexual y de conquista de mujeres, y demás (Kimmel 1997). En definitiva, la expresión exagerada de eso a lo que otros autores como Connel se han referido como 'masculinidad hegemónica' (Connel [1993] 2005, 77).

Otras canciones de rock español donde encontramos a este canallita machirulo serían, por ejemplo, "Sperman" y "Cuento para mayores" de la banda segoviana Lujuria, "Desde que ya no eres mía" de Los Zigarros, "Sufre mamón" de Hombres G o las ya mencionadas "Hoy voy a asesinarte" de Siniestro Total, "La maté porque era mía" de Platero y tú" y "La mataré" de Loquillo y los trogloditas. Los ejemplos son infinitos. En Sperman encontramos una letra que habla de un superhéroe que nos va a liberar de "falsas promesas beatas" y "viejas creencias pasadas", que no son ni más ni menos que referencias a la represión sexual de la que supuestamente el rock nos libera. Tal y como dicen hacia el final de la canción: "Sperman, se acabó la censura / Sperman, fin de la represión". Sin embargo, al mismo tiempo, esta canción critica a Superman porque es 'empalagoso' y va 'bien peinado', incidiendo en elementos que irían en contra de la masculinidad tradicional y, por lo tanto, en contra de la figura del 
canallita machirulo. Esto es así porque la referencia al carácter empalagoso de Superman y al hecho de que vaya bien peinado introducen una cierta feminización del personaje -puesto que muestra características tradicionalmente entendidas como femeninas como lo son sentimientos de amor y la preocupación por su apariencia física- algo que lo imposibilita para conseguir esa liberación sexual estrictamente masculina que nos presentan. Más claro queda aún en el caso de Batman, sobre el cual dicen que anda de fiesta en fiesta trabajando de drag-queen. Estos modelos de superhéroe no sirven, les falta masculinidad y, por eso, la letra habla de que la salvación viene de la mano de Sperman, el superhéroe machirulo con nombre de semen, de 'esperma'.

En el caso de "Cuento para mayores", la letra nos habla de un 'hado madrino' que con su 'vara mágica' va por el mundo encantando doncellas. En esta canción se presentan tres figuras femeninas, Blancanieves, Caperucita y la sirenita, y todas parecen haber sido ayudadas por el 'hado madrino' y su varita. Además de esta evidente metáfora sexual en la que un hombre con su falo consigue ayudar y salvar a estos personajes femeninos, la canción también nos dice que el 'hado madrino' no puede parar de buscar "lindas princesas para encantar" y que todo se debe a su 'instinto animal'. Un instinto animal que, según esta canción, es imposible -o innecesario- reprimir. Coincidentemente, en una entrevista publicada en El Heraldo del Henares, Óscar Sancho, cantante de Lujuria, indica muy poco convincentemente que en esta canción intenta romper con los estereotipos de género clásicos de los cuentos de niños (2019). Por esa razón introduce un 'hado madrino' y unas princesas que tienen relaciones sexuales y que no aparecen pasivas y sin agencia como en los cuentos tradicionales. Sin embargo, estamos hablando de una letra en la que, literalmente, un hombre salva a tres mujeres con su pene y va buscando más mujeres que encantar porque no es capaz de reprimir -o no quiere reprimirsu instinto animal.

En los casos de "Desde que ya no eres mía" de Los Zigarros y "Sufre mamón" de Hombres G, estaríamos ante una situación en la que el canallita machirulo ve a la mujer como una posesión y en la que su pérdida lo hace derivar en un comportamiento violento e impulsivo para salvar su masculinidad herida. En "Desde que ya no eres mía" se habla de una mujer que desde que 'ya no es' de la voz masculina cantante parece haber adquirido unas libertades con las que él no está de acuerdo. Anda 'de bar en bar', "moviendo las caderas como una loca", "subiendo a los coches de los demás" y "mojando la cama con niños guapos de la ciudad". Esta falta de control sobre la mujer causa en la voz cantante una angustia que, tal y como dice el estribillo, va a hacerle "perder 
la cabeza otra vez". Aunque se plantee en términos románticos, lo que esta canción presenta es una expareja controladora y obsesionada que no puede soportar que su pareja siga con su vida y que esto lo lleva a cierta 'locura'. Cierta 'locura' que muchas veces lleva a episodios trágicos en los que el hombre determina acabar con la vida de su expareja bajo esta nébula romántica de angustia masculina que el abandono parece causar.

En el caso de Los Zigarros, no sabemos exactamente de qué manera pierde la cabeza este personaje. En el de "Sufre mamón" de Hombres G, esto queda algo más claro. En esta ocasión, estamos ante la historia de un hombre que es abandonado por su pareja porque esta decide establecer una relación sentimental con otro hombre. Tras este evento, el primer hombre se enfrenta al segundo exigiendo que le devuelva a 'su chica' en una pelea de gallos donde lo que se intenta es salvar la masculinidad herida del primer hombre. La canción comienza con la voz masculina protagonista llorando y sufriendo por ver a su expareja con otro hombre. Sin embargo, el canallita machirulo no se permite este tipo de actitud 'afeminada' -los hombres no lloran-y pronto se encomienda a la elaboración de un plan para vengarse de la nueva pareja de su ex, quien le ha robado la mujer que 'le pertenece' o como él dice: le ha robado a 'su chica'. Este plan incluye adoptar una actitud violenta y atacar a la nueva pareja de la chica con polvos pica pica, quemarle su jersey y destrozarle el coche. Junto a esto, el protagonista de la historia también disputa su masculinidad intentando emascular a su contrincante llamándolo 'marica': "voy a vengarme de este marica". Tal y como Kimmel indica "the fear of being seen as a sissy dominates the cultural definitions of manhood" (Kimmel 1994, 130) y es precisamente eso lo que el hombre protagonista intenta al llamar 'marica' a su contrincante: caracterizarlo como menos hombre para a su vez presentarse a él como el verdaderamente representante de la masculinidad. Por supuesto, todo esto no es más que una respuesta para salvar su honor y su masculinidad herida por haber sido abandonado por su antigua pareja.

\section{MÁS MASCULINIDADES DEL ROCK ESPAÑOL}

A modo de conclusión, podríamos decir que la figura del canallita machirulo representa un arquetipo que -coincidiendo con las lecciones del patriarcadocosifica a la mujer, presenta un carácter posesivo frente a esta, recurre a la violencia si es necesario para salvaguardar su masculinidad, intercambia gui- 
ños y risas con el resto de sus camaradas masculinos cuando sexualizan a alguna mujer y, además, tiende a verse a sí mismo como una figura rebelde por su supuesta oposición a la sociedad puritana dominante. Sin embargo, merece la pena indagar aún más y estudiar más profundamente también otras masculinidades como, por ejemplo, las de las canciones con hombres despechados y lacrimógenos que construyen la imagen de una 'femme fatal' que les hace daño, situándose a ellos como víctimas de esa 'mala mujer', o la de los hombres que masculinizan elementos tradicionalmente femeninos -como las mallas y pelos largos cardados- para, tal y como Coates indica, "assert power over them and over the 'femenine' or the female" (Coates 1997, 56). Además, también se podría profundizar más en los aspectos estéticos de la música, en la puesta en escena de los músicos, y otros elementos que también tienen una lectura de género desde las teorías sobre la masculinidad.

Por último, también es importante destacar que existen movimientos enteros que cuestionan y subvierten este tipo de masculinidades dentro del rock, como el Queercore o el movimiento Riot Grrr. Estos movimientos introducen perspectivas queer y feministas que construyen formas de entender la masculinidad y los roles de género muy diferentes a los que hemos venido comentando. Con todo, lo verdaderamente importante en lo que nos incumbe en este ensayo es explicitar diferentes instancias en las que el canallita machirulo se manifiesta en el rock español para poder así identificarlas y neutralizarlas. Sirva, por tanto, este breve ensayo como un primer acercamiento a un estudio más profundo sobre las masculinidades que el rock español construye -y que tan influyentes han sido en la configuración de identidad de tantos hombrespara que vayamos más allá de la cansina cantaleta sobre el machismo del reggaetón y el trap, que no acaba sino siendo una manera de delegar responsabilidad y arrojar culpa sobre la juventud actual para no mirar hacia dentro de uno mismo y sentirse libre de pecado.

\section{Referencias bibliográficas}

Coates, Norma. 1997. "(R)evolution now? Rock and the political potential of gender”. En Sexing the groove: Popular music and gender, edited by Sheila Whitely, 50-64. London: Routledge

Cohen, Stanley. (1972) 2002. Folk devils and moral panics: The creation of the mods and rockers. London: Routledge

Connel, Raewyn. (1993) 2005. Masculinities. Berkeley CA: University of California

Eyerman, Ron \& Andrew Jamison. 1998. Music and social movements: Mobilizing traditions in the Twentieth Century. Cambridge: Cambridge University 
Flood, Michael. 2007. "Men, sex, and homosociality: How bonds between men shape their sexual relations with women". Men and Masculinities 10(3): 339-59. https://doi. org/10.1177/1097184X06287761

Frith, Simon \& Angela McRobbie. 1990. "Rock andsSexuality". En On record: Rock, pop and the written word, edited by Simon Frith \& Andrew Goodwin, 317-33. London: Routledge

Frith, Simon. 2007. "Music and identity". En Taking popular music seriously: Selected essays. London: Ashgate

Keith, Thomas. 2021. The bro code: The fallout of raising boys to objectify and subordinate women. New York: Routledge

Kimmel, Michael S. \& Amy Aronson, eds. 2004. Men \& masculinities: A social, cultural and historical encyclopedia. Santa Barbara CA: ABC-CLIO

Kimmel, Michael. 1994. "Masculinity as homophobia". En Theorizing masculinities, edited by Harry Brod \& Michael Kaufman. Thousand Oaks CA: Sage

Martin, Christopher R. 1995. "The naturalized gender order of rock and roll". Journal of Communication Inquiry 19(1): 53-74

McClary, Susan. 1991. Feminine endings: Music, gender, and sexuality. Minneapolis MN: University of Minnesota

Mulvey, Laura. (1974) 1999. "Visual pleasure and narrative cinema". En Film theory and criticism: Introductory readings, edited by Leo Braudy \& Marshall Cohen, 833-44. New York: Oxford University

Pascoe, Cheri Jo. 2007. Dude you are a fag: Masculinity and sexuality in high school. Berkeley CA: University of California

Reynolds, Simon \& Joy Press. 1995. The sex revolts: Gender, rebellion and rock'n'roll. Cambridge MA: Harvard University

Sancho Rubio, Oscar. 2019. "Óscar Sancho, de Lujuria: 'Nos llamaban machistas por hablar de sexo, pero si no somos sexualmente libres no seremos libres'". Crónica y entrevista de Estrellas de Metal. 1 podcast audio, 29:30. El Heraldo del Henares, 25 dic. https://www. elheraldodelhenares.com/cult/oscar-sancho-de-lujuria-nos-Ilamaban-machistas-por-hablar-de-sexo-pero-si-no-somos-sexualmente-libres-no-seremos-libres/

Shumway, David R. 2014. Rock star: The making of musical icons from Elvis to Springsteen. Foreword by Anthony DeCurtis. Baltimore: Johns Hopkins University

\section{Discografía citada}

Coz. 1980. "Más sexy”. Pista 1 en Más sexy. Epic

— . (1980) 2006. "Más sexy" Publicado por Unacanciónunrecuerdo. Vídeo de Youtube, 3:47, 13 nov. https://www.youtube.com/watch?v=kE7tYo49VRs

Hombres G. 1989. "Sufre mamón". Pista 1 en Voy a pasármelo bien. CBS Records

Los Ronaldos. 1987. "Sí, sí". Pista 11 en Los Ronaldos. EMI

Los Zigarros. 2014. "Desde que ya no eres mía". Pista 4 en Los Zigarros. Universal Music Spain

Lujuria. 1995. "Cuento para mayores". Pista 9 en Cuentos para mayores. Locomotive Music

— . 1999. "Sperman". Pista 7 en Sin parar de pecar. Locomotive Music. 
— . 2015. "Esta noche manda mi polla". Pista 1 en Esta noche manda mi polla. Maldito Records

Mago de Oz. 2000. "Polla dura no cree en dios". Pista 7 en Finisterra. Locomotive Records

Notas

${ }^{1}$ Cohen habla de pánico moral cuando una "condition, episode, person or group of persons emerges to become defined as a threat to societal values and interests".

${ }^{2}$ Dos trabajos que también tratan esta y otras ideas en torno a la rebelión y el género de la juventud del rock son The Sex Revolts. Gender, Rebellion and Rock'n'Roll de Simon Reynolds y Joy Press y "The Naturalized Gender Order of Rock and Roll” de Christopher R. Martin

(Artículo recibido: 21-03-21; aceptado: 24-06-21) 